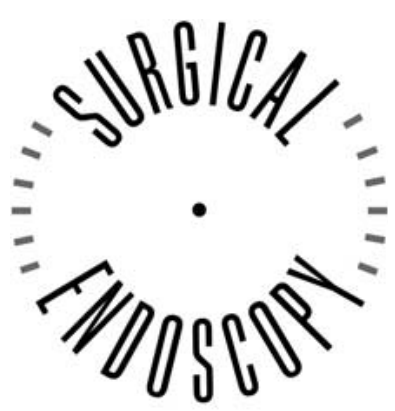

and Other Interventional Techniques

\title{
Effects of the aldosterone receptor antagonist potassium canrenoate on renal blood flow and urinary output during prolonged increased intraabdominal pressure (IAP) in pigs
}

\author{
F. F. Gudmundsson, ${ }^{1}$ A. Viste, ${ }^{1}$ O. L. Myking, ${ }^{2}$ K. Grong, ${ }^{1}$ K. Svanes ${ }^{1}$ \\ ${ }^{1}$ Surgical Research Laboratory, Department of Surgical Sciences, University of Bergen, 5021-Bergen, Norway \\ ${ }^{2}$ Institute of Clinical Chemistry, University of Bergen, 5021-Bergen, Norway
}

[Surg Endosc (2004) 18: 1528-1534, DOI: 10.1007/s00464-003-9295-2]

The corrected affiliations for the authors are printed here. 